Days 1 and 2 were detrimentally affected by alcohol.

The relearning scores of the A-B items were submitted to a 2 by 2 factorial analysis of variance to assess the effects of a drug-state change. None of the F ratios were significant. Neither drug state on Day 1 (O) nor drug state on Day 2 (T) contributed to performance on Day 2 . More important, it was observed that the $\mathrm{O}$ by $\mathrm{T}$ interaction (drug-state change) was not significant. Thus, contrary to expectation, no differences in relearning were found between the groups; relearning was not influenced by a drug-state change.

The effects of a drug state change on negative transfer were assessed first by comparing performance on the C-D and $A-B_{r}$ items within each group by means of correlated t tests, and second by computing the absolute amount of negative transfer by comparing the number of trials required by each group to learn the $A \cdot B_{r}$ items. In the $A-A$ group the $A-B_{r}$ items were significantly more difficult to learn than the C-D items, indicating negative transfer $(\mathrm{t}=5.55, \mathrm{p}<.01)$. No differences were observed between the two transfer lists in the A-P group $(\mathrm{t}=0.63$, n.s.). The $A-B_{r}$ items were learned more quickly than the C-D items in the P-A group $(t=2.55$, $p<.05$ ), indicating the absence of negative transfer. In the P.P group the A-B $B_{r}$ items took significantly longer to learn than the C-D items $(\mathrm{t}=4.39, \mathrm{p}<.01)$, illustrating negative transfer. Thus, on within-group comparisons, those groups that were in the same drug state on both days manifested negative transfer, while the groups that had a change in drug state did not.

The absolute amount of negative transfer between groups was determined by submitting the number of trials required to reach criterion scores on the A-B $B_{r}$ items to an analysis of variance. An overall main effect for drug state was significant $(F=6.52, p<.05)$. A Sheffé test was computed to compare the groups that were in the same drug state with those that had a change of drug state. The difference between the groups was found to be significant $(\mathrm{p}<.05)$, thus demonstrating that there was a greater absolute amount of negative transfer in the two groups that were in the same drug state on both days as compared to the groups who had a change of state.

\section{DISCUSSION}

Ingestion of alcohol retarded both original learning on Day 1 and new learning on Day 2. This finding provides confirmation for the notion that acute alcohol consumption is detrimental to learning (Goodwin et al, 1960; Storm \& Caird, 1967).
Relearning was not affected by a drug-state change. This may be due to several factors. Because there were only three items, relearning may have occurred too rapidly for any group differences to emerge. An alternative explanation of this result may be that relearning as an index of memory is not sensitive to detecting the effects of a drug-state change. That not all types of memory are influenced by a drug-state change has already been demonstrated (Goodwin et al, 1969).

Negative transfer effects were found to be susceptible to a drug-state change. Both groups (A-A and P-P) which were in the same drug state on both days evidenced negative transfer, while the groups that had a change of drug state (A-P and P-A) did not. This finding is in agreement with that reported by Goodwin et al (1969), who observed that there was less interference of learning of an avoidance task following a change in drug condition.

In summary, this experiment lends further support for the notion that state-dependent learning can be demonstrated in humans with alcohol. However, the results also suggest that not all forms of memory are disrupted by a change in drug state, a finding in agreement with that reported by Goodwin et al (1969). The mechanisms responsible for state-dependent learning cannot at present be delineated. Whether or not dissociation can be invoked to explain such clinical characteristics of chronic alcoholism, such as blackouts and "loss of control," as suggested by Storm \& Smart (1965), must also await further clarification.

\section{REFERENCES}

ARCHER, E. Re-evaluation of the meaningfulness of all possible CVC trigrams. Psychological Monographs, 1960, 70 (Whole No. 497).

BUSTAMANTE, J., ROSELLO, A., JORDON, A., PRADERE, E., MARTINEZ, H., \& INSUA, A. Learning and drugs. Paper presented at the Psychopharmacological and Conduct Regulation Symposium. Eighteenth International Congress of Psychology, Moscow, 1966. (Abstract).

GOODWIN, D., POWELL, B., BREMER, D., HORNE, H., \& STERN, J. Alcohol and recall: State-dependent effects in man. Science, 1969 , $163,1358=1360$.

OVERTON, D. Dissociated learning in drug states (state-dependent learning). Paper presented at the meeting of the American College of Neuropharmacology, San Juan, Puerto Rico, 1967.

STORM, T., \& CAIRD, W. The effects of alcohol on serial verbal learning in alcoholics. Psychonomic Science, 1967, 9, 43-44.

STORM, T., \& SMART, R. Dissociation: A possible explanation of some of the features of chronic alcoholism and implications for treatment. Quarterly Journal for Studies on Alcohol, 1965, 26, 111-115.

THORNDIKE, E., \& LORGE, I. The teacher's word book of 30,000 words. New York: Bureau of Publications, Teachers College, Columbia University, 1944.

\title{
Varying amount of static visual noise and the Ansbacher effect*
}

\author{
GORDON STANLEY \\ University of Melbourne, Parkville, Victoria 3052, Australia
}

Ss viewed either a stationary or a moving illuminated arc line in one of four conditions: no static visual noise or $5 \%, 25 \%$, or $45 \%$ static visual noise. The visual noise consisted of randomly placed light circles of $1-\mathrm{cm}$ diam optically superimposed on the surface of the disk on which the arc line was located. An analysis of variance based on the median magnitude estimates of arc length yielded no significant noise effect, but a significant static/dynamic effect indicating contraction with movement (the Ansbacher effect). These results are discussed in relation to other research on the Ansbacher effect.

The Ansbacher effect refers to the appearance of contraction when an illuminated arc line moves in a circular path around a central fixation point. The contraction occurs as an increasing

*The author is grateful to J. Darvall for assistance in data collection and D. C. Finlay for assistance in data analysis. This experiment forms part of a project entitled, "Experiments on the Perception of Movement," supported by the Australian Research Grants Committee (Grant A67/16441). function of speed when the background is dark (Ansbacher, 1944). Marshall \& Stanley (1964) and Stanley (1966) reported that no contraction occurred with movement of a black arc on light surrounds. Attempts at explaining the phenomenon have been couched in terms of the perceptual-moment hypothesis (Ansbacher, 1944) or in terms of excitation/inhibition processes (Stanley, 1967, 1968). 
The difference between the light arc on dark-surround (contraction) and the dark arc on light-surround (no contraction) conditions was seen as evidence that the relative state of adaptation of the eye to light is an important parameter determining the effect. However, Stanley (1970) reported an increase in contraction when a pattern of static visual noise (randomly placed $1-\mathrm{cm}$ squares of light) was superimposed onto the dark surrounds of the disk on which the light is rotated. The amount of visual noise was relatively small, representing only $1.6 \%$ of the surface area of the disk. Stanley \& Jackson (in press) found that light arcs on the dark sectors of half-light half-dark disks did not contract. This finding is consistent with the interpretation that the relative state of adaptation of the eye is important and suggests that with increasing amounts of visual noise contraction should decrease The present experiment was designed to examine the effect on contraction of increasing the amount of static visual noise from $5 \%$ to $45 \%$ on the surface area of the dark disk.

\section{SUBJECTS}

The 64 male and 64 female Ss were paid volunteer undergraduates from the University of Melbourne. All were naive with respect to the Ansbacher effect and had normal or corrected-to-normal vision in their right eyes.

\section{APPARATUS}

The apparatus was essentially as described in previous reports (Stanley, 1966, 1967). An arc line of luminance $1.8 \log \mathrm{fL}, 12$ or $6 \mathrm{~cm}$ long and $0.4 \mathrm{~cm}$ wide, was located at a radial distance of $21 \mathrm{~cm}$ from the center of a black disk. The disk was exposed by a shutter for 2 sec on each trial and was located at a distance of $100 \mathrm{~cm}$ from $\mathrm{S}$. For the present experiment the disk was stationary or rotating at $75 \mathrm{rpm}$. A partial mirror was placed on S's side of the shutter to enable the constant presence of a fixation light, which was aligned with the optical axis of the equipment. The visual noise consisted of light circles $(1.5 \log \mathrm{fL}), 1 \mathrm{~cm}$ in diam, selected at random from a square $50 \times 50 \mathrm{~cm}$ matrix. This display was located at the same distance from the $S$ as the disk $(100 \mathrm{~cm})$ and was optically superimposed onto the disk by means of a large sheet of glass that acted as a partial mirror. The number of randomly placed circles varied so that the total amount of illuminated area superimposed was equivalent to $5 \%, 25 \%$, or $45 \%$ of the surface area of the disk. The $\mathrm{S}$ always viewed the disk through the glass sheet, which was located on the apparatus side of the shutter. On trials in which the noise was not presented, the noise display was covered by a black metal screen, but the observations were still made looking through the glass sheet.

\section{EXPERIMENTAL DESIGN}

The three conditions of visual noise and a zero noise control were presented with the arc either stationary or moving, making eight experimental conditions. Sixteen Ss, eight male and eight female, were assigned randomly to each of the eight experimental conditions. For each condition, Ss were presented with two lengths of line, 6 or $12 \mathrm{~cm}$, for a total of 10 trials for each length. The order of presentation of these trials was randomized with a run restriction of no more than three presentations of the same length.

\section{PROCEDURE}

The Ss were tested individually and seated at a table behind the shutter in the $S$ booth. The S's right eye was aligned in the optical system so that the fixation light was located at the center of the disk. The $S$ was read the usual instructions (Stanley, 1966), which ask him to keep fixating the center and view only the outside arc out of the corner of his eye, making estimates of its length in inches or fractions of an inch.

\section{RESULTS}

The median of each 10 trials was calculated for each $\mathrm{S}$ for each length, and an analysis of variance based on these median scores was computed. The main effect of noise was not significant $(F=1.05, \mathrm{df}=3 / 128, \mathrm{p}>.05)$, but the main effects of static/dynamic $(\mathrm{F}=135.58, \quad \mathrm{df}=1 / 128, \quad \mathrm{p}<.01)$ and length $(F=319.79, \mathrm{df}=1 / 120, \mathrm{p}<.01)$ were significant, as was the Static/Dynamic by Length interaction ( $F=104.197$, $\mathrm{df}=1 / 120, \mathrm{p}<.01)$. Figure 1 shows a plot of the group mean estimates for each experimental condition. It can be seen that the presence of increasing amounts of visual noise does not reduce the apparent contraction of the moving arc line.

\section{DISCUSSION}

In the present experiment the smallest amount of visual noise presented (5\%) was more than the amount used by Stanley (1970), who found a statistically significant increase in contraction in the presence of $1.6 \%$ of static visual noise. In the Stanley (1970) study the noise and no-noise functions of apparent arc length as a function of speed converged with increase in speed, showing less difference between the two conditions at the greatest speed. The speed of arc rotation used in the present study corresponded to the maximum speed used in the earlier study. There were minor differences between the noise displays in the two studies $1-\mathrm{cm}$ squares of equal luminance to the arc were used in the previous study and $1-\mathrm{cm}$-diam

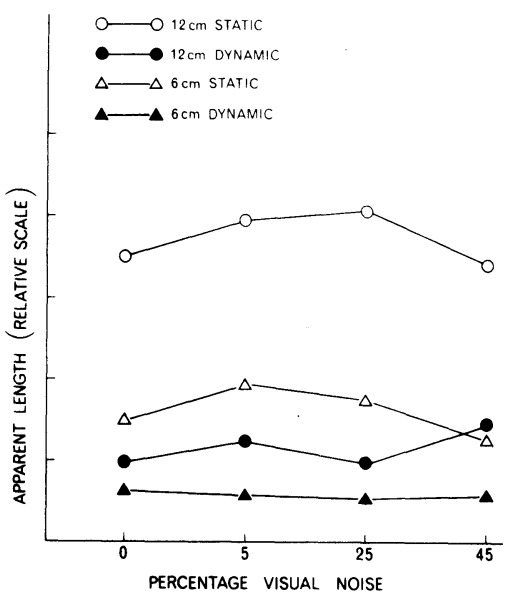

Fig. 1. Group mean magnitude estimates of length plotted against percentage visual noise for each length under static and dynamic conditions.

circles of lesser luminance than the arc were used in the present study. Despite these differences between the two studies, the consistent finding is that the presence of static visual noise does not result in a decrease in contraction, and this finding holds even when the noise is equivalent to $45 \%$ of the surface area of the disk.

Stanley \& Jackson (in press) showed that light arcs on the dark sectors of half-dark half-light disks did not contract. However, in their study the sectors were also in rotation and maintained a constant speed relative to the arc. It is possible that this temporal relation of the additional light area to the arc is responsible for the breakdown of contraction. Alternatively, the difference in the distribution of the additional light may be responsible for the difference between their result and that of the present experiment.

\section{REFERENCES}

ANSBACHER, H. L. Distortion in the perception of real movement. Journal of Experimental Psychology, 1944, 34, 1-23.

MARSHALL, A. J., \& STANLEY, G. The apparent length of light and dark arcs seen peripherally in rotary motion. Australian Journal of Psychology, 1964, 16, 120-128.

STANLEY, G. Apparent shrinkage of a rotating arc as a function of luminance relations between figure and surround. Acta Psychologica, 1966, 25, 357-364.

STANLEY, G. Light summation and the perceived length of moving lines. Acta Psychologica, 1967, 26, 260-264.

STANLEY, G. Exposure-time and the apparent length of an illuminated rotating arc-line. Perception \& Psychophysics, 1968, 4, 71-72. STANLEY, G. Static visual noise and the Ansbacher effect. Quarterly Journal of Experimental Psychology, 1970, 22, 43-48.

STANLEY, G., \& JACKSON, R. The apparent lengths of arcs on white and black sectors of rotating discs. Australian Journal of Psychology, in press. 